\title{
O desafio de formar mestres e doutores numa instituição pública
}

A aprovação de uma dissertação ou de uma tese publicamente defendida perante uma banca examinadora de expertises, se constitui na etapa final que assegura a conclusão do mestrado ou do doutorado por parte dos pós-graduandos regularmente matriculados. Esta condição caracteriza a singularidade que é própria dos programas de pós-graduação stricto sensu. Assim sendo, busca-se através do mestrado qualificar profissionais para o exercício do magistério e através do doutorado a formação de pesquisadores.

Uma vez aprovado este tipo de Trabalho de Conclusão do Curso (TCC), o pós-graduando se torna apto à diplomação. Para tanto, o colegiado do programa, após minuciosa avaliação do cumprimento de toda a legislação pertinente, homologa o resultado final conquistado, e encaminha a documentação aos órgãos superiores da universidade para que seja autorizada a emissão do diploma de mestre ou de doutor.

O texto final da dissertação ou da tese se configura num rico substrato gerador de um ou mais artigos a serem submetidos aos mais diversos periódicos científicos especializados, nacionais e internacionais, reconhecidos como de alto impacto. Para a consecução deste objetivo o programa de pós-graduação, através dos seus professores orientadores, deve estimular e supervisionar a produção e submissão de artigos pelos pós-graduandos sob sua responsabilidade.

Não obstante a racionalidade desta trajetória, a realidade cotidiana tem demonstrado ser um desafio enfrentado pelos pós-graduandos e seus orientadores, a aceitação de artigos pelos mais diversos periódicos científicos, reconhecidamente considerados de impacto - de acordo com a recente classificação estabelecida pelo sistema de avaliação Qualis CAPES, prioritariamente, A1, A2, A3 e A4. Contudo, não se pode perder de vista que cada periódico tem o seu próprio tempo para deliberar quanto à aceitação ou não dos artigos submetidos a fim de serem divulgados nas suas respectivas plataformas.

Note-se que são sucessivas as tentativas para se alcançar a aceitação para publicação de um artigo junto aos diferentes editores de vários periódicos em ocasiões distintas. Registre-se que diversos colegiados tem acompanhado o fluxo de excelentes mestrandos e doutorandos que muito embora, tenham aprovado seu trabalho de conclusão em defesa pública devidamente autorizada pelo programa de pós-graduação, necessitam, ainda, de vários meses para ter os seus artigos aceitos pelos periódicos, apesar da solidariedade e cumplicidade dos seus orientadores enquanto copartícipes das publicações. Só após a realização de consecutivos ajustes solicitados pelos revisores, é que os autores têm a satisfação de ver seu artigo recomendado e aceito para publicação.

Se, de um lado, o conceito a ser atribuído pela CAPES a um programa de pós-graduação depende da expressiva qualidade e do relevante número de produções científicas qualificadas, de outro, não se pode postergar a defesa pública da dissertação ou da tese por mais de vinte e quatro ou quarenta e oito meses contados a partir do ingresso do mestrando ou do doutorando no programa, sob o argumento de que o mesmo não recebeu, até então, a notificação de aceitação dos seus artigos pelos periódicos. Se assim proceder, o programa de pós-graduação ao ser avaliado, certamente, estará sendo penalizado por ultrapassar o tempo limite, vindo a correr o risco de rebaixamento da nota a ser atribuída pela CAPES no quadriênio, comprometendo, de forma irreversível, inclusive, as bolsas e os investimentos conquistados para os seus próprios pós-graduandos.

Este entendimento respalda, incondicionalmente, a trajetória qualitativa dos programas de pós-graduação do Instituto de Ciências da Saúde da Universidade Federal da Bahia. Para tanto, tome-se como referenciais as trilhas pautadas pelos Programas de Pós-graduação Processos Interativos dos Órgãos e Sistemas, Imunologia e Biotecnologia. 
No particular, o Programa de Pós-graduação Processos Interativos dos Órgãos e Sistemas da Universidade Federal da Bahia, é uma iniciativa acadêmica interdisciplinar constituída pela área de concentração denominada "Estudos Integrados dos Órgãos e Sistemas". Já o Programa de Pós-graduação em Imunologia imprime suas linhas de pesquisa numa área de concentração voltada à formação estrita de mestres e doutores especializados em Imunologia e áreas correlatas. Por sua vez, o Programa de Pós-graduação em Biotecnologia é modelado pelas áreas de concentração intituladas Biotecnologia Industrial e Ambiental, Biotecnologia de Insumos Biológicos e Biofotônica e Nanotecnologia.

De mais a mais, breve consulta às plataformas Lattes e Sucupira revela quadros docentes extremamente produtivos, assim como, os diversos projetos de pesquisa concluídos e em processo de execução que despontam relevância e consistência.

Dessa maneira, sem dúvida alguma, os mestrados e os doutorados oferecidos pelo Instituto de Ciências da Saúde têm como objetivo permanente contribuir com o desenvolvimento de uma política de promoção e avanço da ciência capaz de gerar o saber renovado na busca pela excelência das práticas de cuidar e administrar.

Roberto Paulo Correia de Araújo

Editor científico da Revista de Ciências da Saúde

Instituto de Ciências da Saúde

Universidade Federal da Bahia 